\title{
Global health diplomacy, national integration, and regional development through the monitoring and evaluation of HIV/ AIDS programs in Papua New Guinea, Vanuatu, and Samoa
}

\author{
Sebastian Kevany ${ }^{1 *}$, Amy Gildea ${ }^{2}$, Caleb Garae ${ }^{3}$, Serafi Moa ${ }^{4}$, Avaia Lautusi ${ }^{4}$
}

\begin{abstract}
The South Pacific countries of Vanuatu, Samoa, and Papua New Guinea have ascended rapidly up the development spectrum in recent years, refining an independent and post-colonial economic and political identity that enhances their recognition on the world stage. All three countries have overcome economic, political and public health challenges in order to stake their claim to sovereignty. In this regard, the contributions of national and international programs for the diagnosis, treatment and prevention of HIV/AIDS, with specific reference to their monitoring and evaluation (M\&E) aspects, have contributed not just to public health, but also to broader political and diplomatic goals such as 'nation-building'. This perspective describes the specific contributions of global health programs to the pursuit of national integration, development, and regional international relations, in Vanuatu, Samoa and Papua New Guinea, respectively, based on in-country M\&E activities on behalf of the Global Fund to Fight AIDS, Tuberculosis (TB) and Malaria and the Australian Department of Foreign Affairs and Trade (DFAT) during 2014 and 2015. Key findings include: (1) that global health programs contribute to non-health goals; (2) that HIV/AIDS programs promote international relations, decentralized development, and internal unity; (3) that arguments in favour of the maintenance and augmentation of global health funding may be enhanced on this basis; and (4) that "smart" global health approaches have been successful in South Pacific countries.

Keywords: HIV/AIDS, Global Health Diplomacy, Monitoring and Evaluation ((M\&E), Samoa, Vanuatu, Papua New Guinea

Copyright: @ 2015 by Kerman University of Medical Sciences

Citation: Kevany S, Garae C, Moa S, Lautusi A, Gildea A. Global health diplomacy, national integration, and regional development through the Monitoring and Evaluation of HIV/AIDS programs in Papua New Guinea, Vanuatu, and Samoa. Int J Health Policy Manag 2015; 4: 337-341. doi: 10.15171/ijhpm.2015.89
\end{abstract}

\section{Article History:}

Received: 13 March 2015

Accepted: 18 April 2015

ePublished: 27 April 2015

\section{Background}

The South Pacific countries of Vanuatu, Samoa, and Papua New Guinea have ascended rapidly up the development spectrum in recent years (1), refining an independent and post-colonial economic and political identity that enhances their recognition on the world stage. This process has not been an easy one, with all three countries having had to overcome economic, political and public health challenges in order to stake their claim to sovereignty, national identity, and internal cohesion (2). In this regard, national and international programs for HIV/AIDS, with specific reference to their Monitoring and Evaluation (M\&E) aspects, have augmented not just public health, but also, as in other settings (3), broader political and diplomatic goals such as 'nation-building', defined here as the societal integration of diverse origins, histories, languages, cultures and religions within the boundaries of a sovereign state (4). This 'perspective' describes the specific contributions of global health programs to the pursuit of national integration, development, and regional international relations, in Vanuatu, Samoa, and Papua New Guinea, respectively, based on the authors' in-country diplomatic and M\&E activities, observations and experiences on behalf of the Global Fund to Fight AIDS, Tuberculosis (TB), and
Malaria ('The Global Fund') and the Australian Department of Foreign Affairs and Trade (DFAT). These missions were conducted in response to a range of challenges that face many low- to middle-income countries from the M\&E perspective, including deficiencies in appropriate equipment, skills, and communications systems (3).

\section{The challenge of regional integration in Vanuatu}

The Republic of Vanuatu has faced considerable challenges in developing a 'national identity' as a result of location, geography and logistics. Covering more than 80 islands across more than 800 square miles, the advancement of regional integration and cohesion since national independence in 1980 has been achieved only through overcoming significant political and economic challenges (5). Since Vanuatu's recognition as an independent state by the United Nations (UN), successive governments have grappled with the challenges posed by creating a unified leadership across a diverse range of settings, cultures and populations (6). Such efforts have demanded contributions from every facet of society (7) and every government department, including joint initiatives between international global health organizations such as the Global Fund and the World Health Organization 
(WHO) with the Vanuatan Ministry of Health (8). Amongst other achievements, such collaborations have sought to advance the vertical, horizontal and diagonal integration of health programs; programmatic impact on local health services; government health ministerial restructuring; and the development of national healthcare strategies in a harmonized and aligned fashion across the island chain (WHO County Office Vanuatu, personal communication, 2014).

The role and resurgence of the Ministry of Health

The Ministry of Health of Vanuatu has been of signal importance in these efforts. Throughout Vanuatu's history of independence, successive governments and ministers have made public health - with its broad reach and focus on accessibility, equity, and equality in service delivery - a lynchpin of national integration efforts (9), defined in this context as "the development and awareness of a common identity amongst the citizens of a country" (10). This 'dual role' of Vanuatu's public health programs was threatened, in recent years, via the pursuit of a highly contentious curative treatment strategy to the exclusion of funding for preventive medicine strategies (11). The subsequent restoration of the original public health paradigm in 2014 (12) has seen a resurgent role for the Ministry of Health, and public health in particular, in promoting both regional integration and preventive medicine.

Other contributions of global health efforts to national integration: monitoring and evaluation (M\&E) of HIV/ AIDS programmes

Efforts made in the design, delivery and M\&E of HIV/AIDS programs in Vanuatu have successfully adapted to this dual role of simultaneously promoting health and well-being whilst also contributing to the development of a national identity in a fashion that has been documented in other contexts (3). The national government has leveraged a range of opportunities to advance national integration, regional cooperation, and public health in concert with each other (13) - not just through the provision of health services, but also in parallel with culturally-appropriate health and education campaigns (14); inter-island supply chain and M\&E activities; and joint national and regional training initiatives that focus on the application of M\&E-driven decision-making in a coordinated and harmonious fashion within and across Secretariat of the Pacific Community (SPC) member countries (15). In particular, the socially, culturally, and economically 'sensitized' nature of HIV/AIDS programs, such as low-cost, inclusive, geographically widespread, and therefore accessible Voluntary Counseling and Testing (VCT) programs, supported by regionally-and linguistically adapted health education initiatives, has helped to ensure that intervention acceptability across Vanuatu's tribes, cultures and islands has led to improved uptake and utilization (16). In addition, the development and support of national M\&E systems under the auspices of the Global Fund (amongst other donors) has been recognized as assisting successive governments in their efforts to both restore the broader public health system to previous standards of service delivery and improve interisland communications, cooperation, and coordination via enhanced reporting systems (17). Specific examples include the development of regional M\&E capacity through trainings on remote islands such as Espirito Santo, the deployment of associated reporting equipment to rural healthcare facilities, and the establishment of harmonized donor and national health surveillance reporting systems (18). Finally, significant related efforts to pursue malaria eradication in Vanuatu (19) have given Vanuatu a unique place, and level of prestige, on the world stage via international publicization of such efforts (20). Through attempts to convince the global community that, via the right programs and international support, malaria eradication at the national level is possible in the 21st century, such efforts have also built and affirmed a positive national and international identity for target countries.

Public health amidst economic transition in Papua New Guinea

Standing on the brink of potentially dramatic economic growth and social change associated with production from the Liquefied Natural Gas (LNG) project, the direction of resource revenues into improved and sustainable public health service delivery offers an opportune vehicle for Papua New Guinea to translate natural resources into human development outcomes (21). In this context, Papua New Guinea has the highest incidence of HIV/AIDS in the Pacific region, and has become the forth country in the Asia Pacific region to be declared a 'generalized epidemic' (22). However, the lack of accurate and reliable surveillance and M\&E data on the epidemic - particularly from remote areas - $(i)$ significantly impacts the accuracy of health status indicators, which risk understating the extent of HIV/AIDS and other infectious diseases such as TB and malaria (23), (ii) limits coordination and harmonization between key stakeholders in healthcare delivery (24), and (iii) constrains both donor and recipient funding and decision-making through the absence of valid, reliable and up-to-date performance data (25).

Opportunities for international relations via enhanced monitoring and evaluation (M\&E) systems

The development of a functioning and cohesive M\&E system in Papua New Guinea has, therefore, been a longstanding concern for donor organizations, focusing both on disease-specific systems (such as those for HIV/AIDS) (26) and broader health systems strengthening initiatives such as training, technical support, and key equipment provision (27). Amongst the donors currently operating in Papua New Guinea, perhaps the most significant, from an international relations perspective, is the Australian DFAT, formerly represented under the auspices of its development arm, AusAid. Given the increasingly significant regional, strategic and economic significance of close relations between Australia and Papua New Guinea, the development of effective and functional M\&E systems fulfills a range of donor goals beyond ensuring quality assurance, transparency, and accountability in service delivery - such as the generation of reliable performance metrics with which to track funding - and as governed by policy initiatives such as the Papua New Guinea and Australia Partnership for Development: Health and HIV Schedule (28). Such collaborations recognize, both implicitly and explicitly, that supporting recipient governments to create an efficient health 
system is both (i) an effective and sustainable approach to improving health service delivery and (ii) contributes to regional and international relations (29), including bridging political, economic, cultural and social differences to advance cooperation between nations.

Translating global health reporting into global health diplomacy

How are enhanced HIV/AIDS M\&E systems leveraged for diplomatic and international relations purposes (3)? Primarily, the production of valid, robust and reliable results of DFAT initiatives helps to strengthen the case for 'value for money' to both donor and recipient governments (23), demonstrating returns on investments and thereby building support for ongoing global health funding to the Australian Parliament $(27,28)$. In this context, broader 'lessons learned' by DFAT in the implementation of Evaluation Capacity Building (ECB) programmes in Indonesia, Timor-Leste, Vanuatu, Fiji, and the Philippines are being accommodated to provide insight into local challenges and opportunities via the application of paradigms such as 'South-South' cooperation and 'triangular assistance' $(30,31)$. Secondly, the production of such results may help to illustrate to the Papua New Guinean Ministry of Health, and the broader national government, that the interests of their country-and there are perhaps none more compelling that the provision of healthcare for infectious diseases (22) - are well-served by the ongoing involvement of external aid and development programs (3), as opposed to adopting 'aid skeptic' stances, as promoted by Zambian economist Dambisa Moyo (32). For this to be achieved, M\&E strengthening has demanded a collaborative approach to capacity-building that appreciates the technical, conceptual and practical challenges faced by health sector implementing partners (33). Thirdly, the generation of M\&E-based communications and reporting systems operating between donor and recipient countries may help to foster broader strategic collaborations, and closer international relations, in an era of heightened international activity and interest in the natural resources of the South Pacific region (34). Taken together, these considerations are of critical importance, not only to global health, but also to regional diplomatic and foreign policy priorities.

Equitable national development through provincial capacity-building in Samoa

In a parallel fashion, though under contrasting circumstances, broader national development in Samoa has been enhanced through HIV/AIDS M\&E systems via concerted efforts by the Global Fund, the World Bank, the United Nations Development Program (UNDP), the WHO, and other donors and international technical advisory bodies (35). The ongoing support by organizations such as the Global Fund for rural antenatal care clinics, for example, encompassing the training and equipping of local nurses to deal with both infectious diseases and associated reporting systems, has provided a vital impetus to both (i) the country's 'health security', in accordance with the WHO's identified regional priorities (36) such as the implementation of international health regulations (37); and (ii) provincial development through the decentralization of (previously-concentrated) health and other public services outside of Apia, the national capital (38). The associated provision of health education to, and access to health services by, provincial populations in provinces such as Sanga, Tumasaga and Shefa therefore represents an advance, not just in the quality of healthcare, but also in the distribution of public services in an equitable fashion throughout the country (39).

Social and cultural consequences of the pursuit of universal testing and coverage

Given the concentrated nature of the HIV/AIDS epidemic in Samoa (40), a unique opportunity exists to achieve two goals that are rarely-attained in developing (or indeed even in developed) countries: (i) universal HIV/AIDS status awareness, and, in conjunction, (ii) universal antiretroviral treatment for all persons diagnosed with HIV/AIDS (41). At present, through the efforts of the Samoan Ministry of Health, working in conjunction with donor organizations such as the Global Fund, all 12 persons who have been diagnosed with HIV/AIDS have been initiated on treatment (Samoan Ministry of Health, personal communication, 2014). Even when considered in the context of the very low reported HIV/ AIDS incidence and prevalence in Samoa (a cumulative total of 23 cases since surveillance efforts began in 1990) $(42,43)$, both universal coverage and Samoa's success in containing the HIV/AIDS epidemic are remarkable achievements. However, given the limited knowledge of HIV/AIDS status, especially in rural areas, resulting in a high probability of undiagnosed HIV-positives (Samoan Ministry of Health, personal communication, 2014), truly 'universal' diagnosis and coverage of HIV/AIDS patients through VCT cannot yet be said to have been substantively achieved. In response, attention to cultural, religious, and social norms in service delivery has formed a key element of improving uptake of HIV/ AIDS testing in the country (44). In particular, both health education efforts to reduce stigma (45) and the development of 'youth-friendly' information centers (42) in response to the vulnerabilities of young people to HIV/AIDS (46) represent key initiatives by the Ministry of Health in this regard over recent years. In the context of the often conservative nature of Samoan society (47), the pursuit of national and post-colonial social and cultural development is therefore also supported by the development of such socially - and culturally - 'sensitized' (48) interventions.

Conclusion: benefits of HIV/AIDS monitoring and evaluation (M\&E) efforts beyond healthcare

Vanuatu, Papua New Guinea, and Samoa, in collaboration with organizations such as the Global Fund and the Australian DFAT have made consistent efforts to ensure that the broader, non-health outcomes of health, HIV/ AIDS and related M\&E activities are, either implicitly or explicitly, optimally realized. In these countries, such 'downstream effects' include, for example, regional centers being addressed with equal importance, from a health service delivery perspective, as regional capitals (41). Similarly, donor organizations' efforts to strengthen $M \& E$ through initiatives such as on-site data verifications and routine service quality assessments, as well as broader health system level M\&E strengthening initiatives (27), have contributed to both 
national and international links and communications at all levels of geographical and service delivery (49). In the most meaningful way, therefore, these 'enlightened self-interest' (50) or 'smart' (51) donor approaches have advanced altruistic and diplomatic goals simultaneously. Related initiatives have, in parallel, and through such multi-level funding rationales, made a profound impact on the control of communicable diseases such as HIV/AIDS and health system strengthening. In a similar fashion, the large-scale and rapid response of regional and other international partners to assist Vanuatu in the wake of the recent and devastating tropical cyclone has advanced, in parallel, regional solidarity, public health, and disaster relief (52). Other small post-colonial nations, in the South Pacific and elsewhere, may have much to learn from these 'smart' approaches to international health and development. In assessing the success of these programs, and in making the case for future donor support, it is therefore of paramount importance to recognize and attempt to optimize and quantify not just their health but also their broader 'nonhealth' outcomes (53).

\section{Acknowledgements}

The authors wish to thank Mr. Troy Stubbings (KPMG Papua New Guinea), Mr. Daniel Khaisir, (KPMG Papua New Guinea), Ms. Christine Soullier (WHO Country office, Vanuatu), Mr. Ronald Ho (KPMG Fiji), Ms. Narisha Karan (KPMG Fiji), Mr. Martin Yala Timothy (KPMG Papua New Guinea) and Ms. Tsvetana Yakimova [The Global Fund to Fight AIDS, Tuberculosis (TB) and Malaria, Geneva, Switzerland].

Ethical issues

Not applicable.

\section{Competing interests}

The authors declare that they have no competing interests.

\section{Authors' contributions}

SK drafted and conceptualized the manuscript. AG provided key input and background on Papua New Guinea. CG provided key input and background on Vanuatu. SM and AL provided key input and background on Samoa.

\section{Authors' affiliations}

${ }^{1}$ University of California, San Francisco, CA, USA. ${ }^{2}$ KPMG Health Advisory Services, Port Moresby, Papua New Guinea. ${ }^{3}$ Ministry of Health, Port Vila, Vanuatu. ${ }^{4}$ Ministry of Health, Apia, Samoa.

\section{References}

1. Asian Development Bank. Asian Development Outlook 2014: Fiscal Policy for Inclusive Growth. 2014. Available from: http:// www.adb.org/sites/default/files/publication/31241/ado2014south-pacific-economies.pdf

2. Aldrich R. The Decolonisation of the Pacific Islands. Itinerario 2000; 24: 173-91.

3. Kevany S, Hatfield A, Workneh N, Aurang Zeb Durrani B, Bekele $\mathrm{Y}$, Khan $\mathrm{U}$, et al. Diplomatic and operational adaptations to global health programs in post-conflict settings: contributions of monitoring and evaluation systems to 'nation-building' in South Sudan. Med Confl Surviv 2012; 28: 247-62. doi: 10.1080/13623699.2012.714654

4. Government of South Africa. What is Social Cohesion and Nation-Building? Department of Arts \& Culture Discussion Document. 2014. Available from: https://www.dac.gov.za/sites/
default/files/WHAT\%20IS\%20SOCIAL $\% 20$ COHESION\%20 AND\%20NATION\%20(3).pdf

5. European Commission. Country Strategy and National Indicative Program: Vanuatu. 10th EDF Program of the European Commission (2008-2013). 2008. Available from: http://ec.europa. eu/development/icenter/repository/scanned_vu_csp10_en.pdf

6. Reuter T. Sharing the Earth, Dividing the Land: Land and Territory in the Austronesian World. Canberra: Australian National University Press; 2006. p. 326.

7. Hess S. Person and Place: Ideas, Ideals and the Practice of Sociality on Vanua Lava, Vanuatu. Berghahn Books; 2009. p. 115.

8. World Health Organization (WHO). Health Service Delivery Profile Vanuatu: 2012. WHO WPRO and Ministry of Health, Vanuatu Official Report. 2012. Available from: http://www.wpro. who.int/health_services/service_delivery_profile_vanuatu.pdf

9. Vanuatu Law Commission. Review of the Dangerous Drugs Act [Cap 12] and the Penal Code [Cap 135]. Issues Paper No. 01 of 2013. 2013. Available from: http://www.lawcommission.gov.vu/ images/pdf/dangerous_drugs.pdf

10. National Institute of Open Schooling (NIOS). National Integration and Secularism. 2014. Available from: http://www.nios.ac.in/ media/documents/secsocscicour/english/lesson-24.pdf

11. Ligo G. Acting Health Director-General removed and replaced. Vanuatu Daily Post, June 27th, 2014. Available from: http://www. dailypost.vu/article_52f059d2-d0db-5840-aeff-a13f78a2141d. html

12. Garae L. Prime Minister's Office confirms Tovu as Health's Acting Director-General. Vanuatu Daily Post, July 1st, 2014. Available from: http://www.dailypost.vu/news/article_109dd6566127-5a70-8347-632b06533ffc.html

13. United Nations International Children's Emergency Fund. Leveraging ICT Effectively to Strengthen HIVIAIDS Treatment \& Care. 2010. Available from: http://www.unicef.org/eapro/Unicef Asia-Pacific_ICT_Assessment_Report_Final_19Jan2011.pdf

14. Vanuatu Daily Post. A long-term solution for public health challenges [internet]. October 18th, 2014. Available from: http:// www.dailypost.vu/news/article_89029f41-a959-557b-a9ab477125d7eaa1.html

15. Prasad BC, Kausimae P. Social Policies in Solomon Islands and Vanuatu. Joint Commonwealth Secretariat and United Nations Research Institute for Social Development Report; 2012.

16. Kalo J. Utilization of Adolescent Reproductive Health Services by Young People in Vanuatu. Ministry of Health and United Nations Population Fund Secretariat of the Pacific Community Joint Report; 2006. Available from: http://countryoffice.unfpa.org/ pacific/drive/AdRHS_Vanuatu.pdf

17. The Global Fund. Pacific Islands Regional Coordinated Country Project on HIV/I AIDS, TB and Malaria [internet]. 2014. Available from: http://portfolio.theglobalfund.org/en/Country/Index/QMJ

18. Government of the Republic of Vanuatu. Health Sector Strategy 2010 -2016: Moving Health Forward. 2014. Available from: http:// www.wpro.who.int/health_services/vanuatu_nationalhealthplan. pdf

19. Feachem $R$, Sabot $O$. A new global malaria eradication strategy. Lancet 2008; 371: 1633-5. doi: 10.1016/s0140-6736(08)60424-9

20. University of California San Francisco. Country Briefing: Eliminating malaria in Vanuatu; 2014.

21. Australian Department of Foreign Affairs and Trade. Papua New Guinea country brief. 2014. Available from: http://www.dfat.gov. au/geo/png/png_brief.html

22. United Nations Programme on HIVIAIDS (UNAIDS). HIV/ AIDS Stakeholder Mapping in Papua New Guinea. UNAIDS Report. 2004. Available from: http://www.hivpolicy.org/Library/ HPP000675.pdf 
23. Commonwealth of Australia. An Effective Aid Program for Australia: Making a real difference - Delivering real results [internet]. 2012. Available from: http://dfat.gov.au/aid/Pages/ australias-aid-program.aspx

24. United Nations Development Program (UNDP). Human Development Report 2014. 2014. Available from: http://hdr.undp. org/sites/default/files/hdr14-report-en-1.pdf

25. [No authors listed]. Evaluation: the top priority for global health. Lancet 2010; 375: 526. doi: 10.1016/S0140-6736(10)60056-6

26. The Global Fund. Grant Portfolio: Papua New Guinea [internet]. 2014. Available from: http://portfolio.theglobalfund.org/en/ Country/Index/PNG

27. Australian Department of Foreign Affairs and Trade (DFAT). Papua New Guinea Health System Capacity Development Program. 2014. Available from: www.dfat.gov.au/about-us/.../ hhsip-health-system-frameworkl.pdf

28. Australian Department of Foreign Affairs and Trade (DFAT). Schedule to the Papua New Guinea-Australia Partnership for Development, Priority outcome 2: Health and HIVIAIDS [internet]. 2014. Available from: http://aid.dfat.gov.au/Publications/ Pages/2659_5398_4695_6862_4723.aspx

29. Michaud J, Kates J. Global health diplomacy: Advancing foreign policy and global health interests. Glob Health Sci Pract 2013; 1: 24-8. doi: 10.9745/GHSP-D-12-00048

30. AusAid. Mid-Term Review (MTR) of Evaluation Capacity Building Program (Indonesia). 2013. Available from: http://www.ode.dfat. gov.au/publications/documents/indonesia-evaluation-capacitybuilding-program-mtr-man-resp.pdf

31. United Nations Economic and Social Council. Trends in SouthSouth and Triangular Development Cooperation. Background Study for the Development Cooperation Forum. 2008. Available from: http://www.un.org/en/ecosoc/docs/pdfs/south-south_ cooperation.pdf

32. The Guardian. Bill Gates and Dambisa Moyo spat obscures the real aid debate [internet]. 2015. Available from: http://www. theguardian.com/global-development/poverty-matters/2013/ may/31/bill-gates-dambisa-moyo-aid

33. Australian Government. Overview of Global Health Initiatives. 2014. Available from: http://aid.dfat.gov.au/aidissues/health/ Pages/home.aspx\#initiatives

34. Winning D. Japan Steps Up Interest in Papua New Guinea's Gas Riches [internet]. The Wall Street Journal; May 23rd, 2013. Available from: http://blogs.wsj.com/moneybeat/2013/05/23/ japan-steps-up-interest-in-papua-new-guineas-gas-riches/

35. World Health Organization (WHO). From Honiara to Apia: Report on Progress and Challenges. 10th International Pacific Health Ministers Meeting. 2013. Available from: http://www.wpro. who.int/southpacific/pic meeting/2013/documents/PHMM PIC10_4_Progress_Report.pdf

36. World Health Organization (WHO) Pacific Regional Office. Samoa National Health Plan - WHO Western Pacific Region. 2007. Available from: http://www.wpro.who.int/health_services/ samoa_nationalhealthplan.pdf

37. Scott A. Global Health Security Under Threat? Progress in implementing the International Health Regulations. Health Diplomacy Monitor; 2012. Available from: http://www. academia.edu/1241479/Global_Health_Security_Under_ Threat_Progress_in_implementing_the_International_Health_Regulations_2005_

38. Leng D. A decentralized primary healthcare model based upon a cost-effective patient data system that includes remote districts and villages in Samoa. Samoan Medical Journal 2010; 2: 35-7.

39. The World Bank. Increasing access to effective, efficient and quality health services in Samoa [internet]. World Bank South Pacific Development Report. 2013. Available from: http://web. worldbank.org/WBSITE/EXTERNAL/NEWS/0,,contentMDK:22 517640 menuPK:141310 pagePK:34370 piPK:34424 theSite PK:4607,00.html

40. World Health Organization (WHO). WHO Country Cooperation Strategy for Samoa 2013-2017. 2012. Available from: http://www. who.int/countryfocus/cooperation_strategy/ccs_wsm_en.pdf

41. World Health Organization (WHO). CSU's Global Fund - related work. 2013. Available from: http://www.wpro.who.int/entity/ country_focus/global_health_initiatives/globalfund/en/

42. United Nations Programme on HIVIAIDS (UNAIDS). Oceania Fact Sheet. 2014. Available from: http://www.unaids.org/ sites/default/files/en/media/unaids/contentassets/documents/ epidemiology/2012/gr2012/2012_FS_regional_asia_pacific_ en.pdf

43. United Nations Programme on HIV/AIDS (UNAIDS). Samoan Global AIDS Reporting Progress Report 2013. Reporting Period: January - December 2013; Report submitted on 31st March 2014. Available from: http://www.unaids.org/sites/default/files/ en/dataanalysis/knowyourresponse/countryprogressreports/201 4countries/WSM_narrative_report_2014.pdf

44. United Nations Programme on HIVIAIDS (UNAIDS). Global AIDS Country Progress Report: Samoa. UNAIDS Report. 2012. Available from: http://www.unaids.org/sites/default/files/en/ dataanalysis/knowyourresponse/countryprogressreports/2012c ountries/ce_WS_Narrative_Report[1].pdf

45. Samoan Red Cross Society. HIVIAIDS in Samoa [internet]. 2014. Available from: http://www.redcross.org.ws/Whatwedo/ Health/HIV/tabid/6588/language/en-US/Default.aspx

46. Buchanan-Aruwafu $\mathrm{H}$. Youth Vulnerability to HIVIAIDS in the Pacific. 2014. Available from: http://www.apcom.org/tl_files/ resources/HIV-Pacific\%20YOUTH\%20VULNERABILITY.pdf

47. Cote JE. A social history of youth in Samoa: religion, capitalism, and cultural disenfranchisement. Int J Comp Sociol 1997; 38: 217-34.

48. Kevany S, Khumalo-Sakutukwa G, Murima O, Chingono A, Modiba P, Gray G, et al. Health diplomacy and adapting global health interventions to local needs in sub-Saharan Africa and Thailand: evaluating findings from Project Accept. BMC Public Health 2012: 12: 459. doi: 10.1186/1471-2458-12-459

49. Secretariat of the Pacific Community. Principal Recipient Annual Report: January to December 2009 [internet]. 2009 Available from: https://www.spc.int/frp/index2.php?option=com docman\&task=doc_view\&gid $=173 \& \mid$ temid $=33$

50. Fauci A. The expanding global health agenda: a welcome development. Nature Med 2007; 13: 1169-71. doi: 10.1038/ $\mathrm{nm} 1646$

51. Center for Strategic and International Studies (CSIS). Final report of the CSIS Commission on smart global health policy. 2010. Available from: http://csis.org/event/rollout-final-reportcsis-commission-smart-global-health-policy

52. International Federation of Red Cross and Red Crescent Societies. Information Bulletin for the Pacific: Tropical Cyclone Pam. 2015. Available from: https://www.ifrc.org/docs/Appeals/15/ IBPacificTC130315.pdf

53. Kevany S. Global Health Diplomacy, 'Smart Power', and the New World Order. Glob Public Health 2014; 9: 787-807. doi: 10.1080/17441692.2014.921219 